\title{
Gaya Kepemimpinan Kepala Sekolah Berbasis Kearifan Lokal, Telaah Terhadap Karakteristik Kepemimpinan Bima "Manggusu Waru" Pada Madrasah Aliyah Negeri 2 Kota Bima
}

\author{
${ }^{1}$ Muhammad lqbal, ${ }^{2}$ Mei Indrajayanti \\ 1,2Dosen Program Studi Pendidikan Biologi, STKIP Bima. Jalan Tendean Kel. Mande Telp. Fax (0374) \\ 42801, Kota Bima-NTB, Indonesia 84117 \\ Email: iqbalstkipbima87@gmail.com
}

\begin{abstract}
Abstrak
The styles or ways of school principals in encouraging the creation of work discipline, work motivation, and the responsibility of teachers for their work are very diverse, one of which is the leadership style of the manggusu waru based school, this study aims to find out how the characteristics of the manggusu waru leadership style in Madrasah Aliyah Negeri 2 Kota Bima. Descriptive qualitative research methods with interview, observation and documentation data sources. The results of the study showed that the eight characteristics of waru manggusu values were set forth in the school restrat and the standard operating procedures for all school staff were inputed on the values of waru manggusu, so that their characters shaped the personality of employees and teachers in Madrasah Aliyah Negeri 2 Kota Bima.
\end{abstract}

Kata Kunci: Gaya Kepemimpinan, Kearifan lokal, Manggusu Waru

\section{PENDAHULUAN}

Kepemimpinan pendidikan yang berhasil apabila berorientasi pada pengembangan mutu untuk peningkatan Sumber Daya Manusia (SDM) yang optimal baik itu Guru, Pegawai, serta Peserta Didik. Salah satu cara terbaik untuk mencapai tujuan tersebut yaitu dengan memberikan motivasi atau dorongan terhadap guru, pegawai dalam bentuk imbalan jasa, penghargaan maupun dukungan, sebagaimana dikemukan oleh Faustino (2003) motivasi kerja seseorang akan meningkat, apabila organisasi tersebut memperhatikan tiga hal yaitu pembayaran atau gaji (pay), sesama pekerja (co-workers), pujian (praise) dan pekerjaan itu sendiri (job itself), sedangkan bagi siswa mutu pembelajaran merupakan sebagian dari motivasi belajar yang telah upayakan oleh guru melalui kinerjanya. Hal ini akan mampu dicapai apabila kepala sekolah mampu menerapkan gaya kepemimpinan yang sesuai dengan harapan kebanyakan orang sehingga orang lain pun terinspirasi dengan kepemimpinan yang diterapkan. Sebab kepemimpinan adalah sebuah gaya prilaku pemimpin dalam mempengaruhi orang lain atau organisasi, sehingga orang lain pun terdorong untuk mengikuti sikap dan watak pribadi pemimpin tersebut kearah pencapaian tujuan organisasi.

Berdasarkan hasil penelitian terdahulu yang dilakukan oleh Septiana, dkk (2013), “ Kepemimpinan Kepala Sekolah Dan Motivasi Kerja Terhadap Kinerja Guru SMP Negeri 
Wonosari" menyatakan kepemimpinan kepala sekolah berpengaruh signifikan terhadap kinerja guru dan kepemimpinan kepala sekolah dan motivasi kerja secara bersamasama berpengaruh signifikan terhadap kinerja guru. Artinya bahwa kepala sekolah menjadi satu penentu penting bagi perputaran roda organisasi terutama pada dunia pendidikan. Oleh sebab itulah tujuan penelitian ini adalah untuk mengetahui gaya kepemimpinan kepala sekolah melalui implementasi model kepemimpinan berbasis manggusu waru.

\section{METODE}

Metode yang digunakan dalam penelitian ini yaitu metode kualitatif dengan menggunakan analisis deskriptif. Analisis deskriptif tujuannya yaitu untuk mengetahui dan mengungkapkan makna dibalik data yang tampak dari gaya kepemimpinan kepala sekolah Madrasah Aliyah Negeri 02 Kota Bima. Adapun alur penelitian ini sebagaimana digambarkan pada bagan di bawah ini.

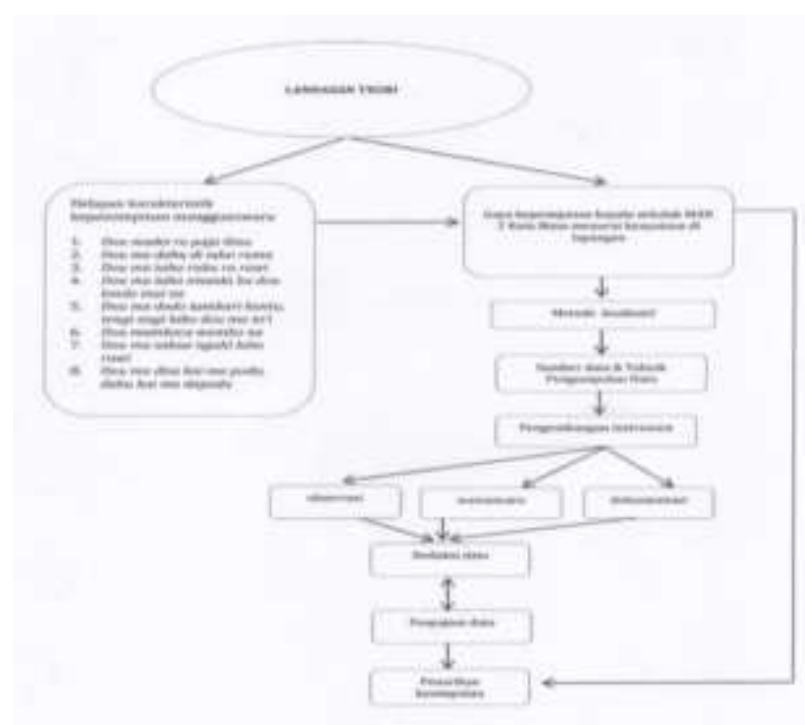

Gambar 1. Alur penelitian gaya kepemimpinan kepala sekolah.

\section{HASIL DAN PEMBAHASAN}

Fungsi-fungsi pokok yang ditampilkan seorang menejer/pimpinan yaitu: terutama pada aspek perencanaan, dimana pemimpin dalam memipin organisasi harus memiliki kemampuan mengkaji kelemahan dan kekuatan organisasi yang di pimpinannya, maka digunakanlah SWOT analisis untuk mengetahui, (1) keinginan dan kebutuhan organisasi, (2) meperhatikan kebutuhan para pengguna, (3) memperhatikan isu-isu yang strategis, (4) dan menentukan strategi, kebijakan, taktik dan program (planning strategis), semua ini dilakukan berdasarkan proses pengambilan kebutuhan secara ilmiah (Fattah: 2011). Dari itulah kepala madrasah 
aliyah negeri 2 kota bima menerapkan gaya kepemimpinan berbasis nggusu waru, dengan menerapkan program dan kebijakan strategis yang telah di masukan dalam Rencana Strategis (Restrat) jangka panjang, menengah dan pendek yaitu dengan menerapkan program 7 hari, antara lain.

\section{Hari Senin: Dou Madei Ro Paja Ilmu artinya Terpelajar Dan Berilmu}

"Dou madei ro paja ilmu" adalah momentum dalam rangka mewujudkan generasi muda yang terpelajar dan berilmu tidak cukup dengan melakukan transpormasi pengetahuan saja yang lebih penting adalah bagaimana membentuk karaktersiswa yang cinta tanah airnya dan memiliki rasa kebangsaan yang kuat melalui pembiasaan wawasan nusantara sehingga melahirkan sikap nasionalisme yang kokoh ditengah-tengah carut-marut persoalan daerah mulai dari konflik politik, agama dan suku serta kelompok bangsa . Pada intinya Dou madei ro paja ilmu ini bertujuan menegaskan bahwa genarasi Indonesia lebih khususnya bima harus memiliki semangat toleransi di antara di antara perbedaan yang ada dengan mengedepankan semangat maja labo dahu.

Kebijakan Strategis: Pada hari senin itu, seluruh guru dapat menyampaikan berbagai hal tentang indonesia; tentang hamparan nusantara dan keunggulannya. Guru dengan berbagai latar mata pelajaran yang dibawakannya, harus mampu mensinergikan apa yang menjadi bahan pembelajaran kepada siswanya dikaitkan dengan keunggulan Nusantara. Contohnya:

(1) Guru Bahasa Inggris harus mampu menceritakan berbagai hal tentang suku sambori dan donggo, yang diceritakan dengan kemampuan Bahasa Inggris guru tersebut. Guru Biologi mampu bagaimana mengamati dan menjelaskan kepada siswa tentang sel hidup dari kerajaan-kerajaan suku mbozo mulai era ncuhi sampai kesultanan, dari berbagai jenis suku adat yang menempati wilayah Bima dan Dompu ini;

(2) Guru Kimia, Fisika, Matematika menghitung berapa cadangan sumberdaya energi yang dimiliki di kota Bima, sumbawa sampai tanah lombok, apa saja yang menjadi sumber mineral unggulannya

(3) Demikian pula dengan guru Bahasa Indonesia, guru sejarah, guru mata pelajaran lainnya bukan hanya menjelasakan disekitar wilayah NTB akan tetapi mampu menjelaskan potensi seluruh 
daerah di indonesia ini, mulai dari tanah yang maha esa dengan menjalankan Papua, tanah Sumatera, Kalimantan, perintahnya dan menjauhi seluruh laranganya. Sulawesi hingga pulau Rote. Guru juga Kebijakan strategis: Pada hari selasa, diharapkan bisa membuka kembali pembelajaran lebih diarahkan pada pengenalan wawasan tentang nusantara dengan seluruh perintah tuhan dan menjelaskan berbagai cara, dengan meningkatkan dampak dari melanggar perintah tuhan disertai minat baca buku wawasan nusantara, dengan pemberian perumpamaan dan cerita penggunaan internet, browsing melalui google dan penggunaan teknologi lainnya. atau risalah. Contohnya pembelajaran biologi dimana allah mengajak manusia untuk Sehingga dari pembelajaran Dou madei ro menjaga kelestarian lingkungan dengan paja ilmu diharapkan akan melahirkan siswa yang mumpuni pengetahuan wawasan nusantara dan potensinya. Lambat laun, siswa merasa bangga sebagai bagian dari negara yang memiliki potensi kekayaan berbagai hal dan siswa berani berdiri tegak dengan penuh percaya diri untuk menatap masa depannya dengan segudang angan dan cita-cita mulia membangun tanah nusantara, memanfaatkan ilmu dan keahliannya untuk kemajuan nusantara

2. Hari selasa: "Dou Ma Dahu Di Ndai Ruma” artinya Bertaqwa Pada Tuhan Yang Maha Esa

Dou ma dahu di ndai ruma maksudnya pada konteks pembelajaran dampak signifikan bagi pembentukan karakter siswa adalah dimana terciptanya siswa yang memiliki nilai ketaqwaan dan tunduk terhadap perintah tuhan mengambil refrensi pada al-qur,an atau hadist serta menjelaskan dampaknya apabila melanggar dengan mengambil sumber refrensi yang sama. Bahasa indonesia pun begitu dengan mengambil ayat-ayat maupun hadist yang menjelaskan dimana tuhan menciptakan beribu bahasa di dunia ini, dan bagaimana cara bertutur bahasa yang baik dan sopan.

Kegiatan Ekstrakurikuler: Solah Dzuhur Berjamaah Sebelum Pulang.

3. Hari Rabu: "Dou Ma Taho Ruku Ra Rawi" artinya Orang yang Berkelakuan Baik.

\section{Pengertian Dou Ma Taho Ruku Ra Rawi} merupakan nilai yang mengandung makna yang dalam yaitu halus tutur kata dan perbuatan serta bersahabat sebagai orang Bima . Di tengah arus modernisme, nilai dan budaya Bima mulai tergerus. Kondisi ini memprihatinkan, dimana generasi muda lupa 
akan identitasnya sebagai masyarakat yang Maja labo dahu. Hal ini merupakan suatu bentuk ikhtiar yang konkrit dalam rangka menghidupkan kembali nilai dan budaya Bima akan eksistensinya tidak terkikis oleh perubahan zaman.

Kebijakan strategis, antara lain yaitu:

(1) Pada hari rabu, siswa dan guru menggunakan pakaian adat Bima, pakaian tradisi baju poro (kebaya) yang berwarna merah lengan pendek bagi perempuan untuk penutup pakaian resmi kerja (keki), sedangkan untuk laki-laki memakai sambolo atau ikat kepala.

(2) Hari spesial untuk menyampai salam, senyum, dan sapah (3S) antara satu sama lain antara guru dengan guru, guru dengan siswa maupun siswa dengan siswa, yang dilakukan sebelum masuk kerja dan kelas pembelajaran.

(3) Guru sebelum memulai pembelajaran atau membuka kegiatan pembelajaran wajib memberikan cerita inspiratif tentang sikap seseorang menjunjung nilai Maja Labo Dahu.

4. Hari Kamis: "Dou Ma Taho Ntanda Ba Dou Londo Mai $\mathrm{Na}$ ” artinya menjaga nasab serta nama baik keluarga. Dan "Dou Ma Dodo Tambari Kontu, Tengi Angi Labo Dou Ma To' $i$ " artinya bahu membahu membantu rakyat kecil.
Artinya pelajar yang telah Di proses pada lembaga pendidikan, diharapkan dapatmembentuk karakter kepemimpinan siswa masa depan membentuk kedewasaan diri dalam penyelesaian masalah kehidupan di tengah merosotnya kedewasan berpikirnya masyarakat, semisa halnya yang terjadi di daerah Bima dan Dompu rata-rata penyelesaian masalah kelompok dan keluarga selalu berakhir dengan keributan. Disini pendidikan Dou ma taho ntanda ba dou londo mai na menjadi harapan untuk membentuk siswa yang dapat menyelesaikan masalah keluarga agar tidak menyebar demi menjaga nasab serta nama baik keluarga, sehingga dengan di dukung oleh semangat "Dou ma dodo tambari kontu, tengi angi labo dou ma to'i . Menjadikan anak memiliki semangat gorong royong serta tanggung jawab terhadap penyelesaian masalah keluarga dan lingkungan dalam bahu membahu membantu rakyat kecil.

Kebijakan strategis : pelajar ilmu sosial baik IPS Terpadu, Kewarganegaraan maupun Sosiologi, diharapkan menjadi medium untuk membentuk kepemimpinan siswa, dengan strategi guru sosial pada saat mengajar menyampaikan masalah sosial mulai dari persoalan konflik, sebab, peran yang diambil serta langkah-langkah yang harus dilakukan, 
sedangkang Kegiatan Ekstrakurikuler yang dilakukan pada hari kamis ini adalah melakukan kegiatan gotong royong dilikungan sekolah dan lingkungan masyarakat sekitar sekolah untuk kegiatan bersih-bersih bersama siswa berserta seluruh pegawai sekolah dan guru, dengan harapan agar siswa dapat lebih mengenal lingkungan sosial dan mengetahui peran-peran sosial yang harus diambil.

5. Hari Jum'at: "Dou Mambeca Wombo $N a$ " artinya kaya serta berbagi dan "Dou Ma Sabua Ngahi Labo Rawi” artinya kejujuran dalam berkata dan berbuat.

Kebijakan Strategis: pada hari jumat guru diharapkan pada setiap akhir pembelajaran dapat menyampaikan beberapa cerita pendek yang memberi hikmah mengenai orang-orang Dou Mambeca Wombo $\mathrm{Na}$ " artinya kaya serta berbagi dan "Dou Ma Sabua Ngahi Labo Rawi" artinya kejujuran dalam berkata dan berbuat. Sedangkan untuk kegiatan ekstrakurikuler yaitu:

(1) Kegiatan " 1 Hari Bersama Dhuafa Untuk Berbagi" dimana pada hari jumat siswa berbagi kepada fakir-miskin dan anak yatim piatu dengan menyisikan uang minimal 500 maksimal 1000 rupiah masing-masing saja setiap siswa untuk mewujudkan "Dou Mambeca Wombo $\mathrm{Na}$ " artinya kaya serta berbagi
(2) Serta kanting kejujuran untuk mewujudkan "Dou Ma Sabua Ngahi Rawi Labo Pahu" artinya kejujuran dalam berkata dan berbuat. Sehingga siswa yang tidak jujur maupun yang jujur dalam pemanfaatan kantin kejujuran akan diberikan panisman dan reward dalam kurung waktu 1 semester

6. Hari Sabtu "Dou Ma Disa Kai Ma Poda, Dahu Kai Ma Dapoda" artinya membela yang benar dan takut membela yang salah.

Pada hari yang ketujuh ini siswa di minta untuk menyampaikan keluh kesahnya pada saat kegiatan ekstrakurikuler yang disampaikan secara langsung pada waktu acara “ 1 Hari Lebih Dekat Bersama Guru” dengan menilai kecakapan dan kesabaran guru pada saat berlangsungnya kegiatan belajar mengajar dalam kurung waktu 1 kali satu minggu semacam Rapor guru yang diberikan oleh siswa. Serta memberikan usul saran kepada pihak sekolah melalui kepala sekolah secara terbuka apa yang harus ditambah dan dibenahi sesuai dengan keinginan siswa. Dalam rangka untuk menciptakan siswa yang "Dou Ma Disa Kai Ma Poda, Dahu Kai Ma Dapoda” artinya membela yang benar dan takut membela yang salah.

Kebijakan Strategis : Pada hari ke Sabtu guru bersama siswa, pegawai dan security 
berkumpul dalam acara " 1 Hari Lebih Dekat Bersama Guru" untuk mendengarkan keluh kesah siswa saat menempuh pembelajaran intrakurikuler maupun ekstrakurikuler. Yang dimana siswa akan memberikan penilaian terhadap kecakapan, kesabaran dan keuletan guru pada saat melaksanakan kegiatan ekstrakurikuler dengan tehnik penyapaian penilain dalam bentuk tulisan kerta yang disertai nama, aspek kelebihan dan kekurangan guru, sekaligus pemberian skor pencapaian prestasi guru. Serta juga siswa dapat memberikan komentar langsung kepada pihak kepala sekolah dengan bahasa tutur kata yang santun terhadap pembenahan sekolah agar mendukung tercapainya siswa "Dou Ma Disa Kai Ma Poda, Dahu Kai Ma Dapoda” artinya membela yang benar dan takut membela yang salah. Adapun Pengembangan Pokok Menejemen Pendidikan untuk Penguatan Kompetensi Guru tentang Pendidikan Karakter Berbasis Manggusu Waru, Yang Meliputi Tahap Perencanaan (Planning), Pengorganisasian (Organizing), Pelaksanaan (Actuating), Dan Pengendalian (Controlling) yang di tuangkan oleh kepala sekolah Madrasah Aliyah Negeri 2 Kota Bima dalam restat, sebagaimana yang tergambarkan pada tabel 1 di bawah ini:
Tabel 1. Menejemen Pendidikan untuk Penguatan Kompetensi Guru Berbasis Manggusu Waru

\begin{tabular}{|c|c|c|c|}
\hline Nis & Hasseve & Me & okenvare \\
\hline 2. & 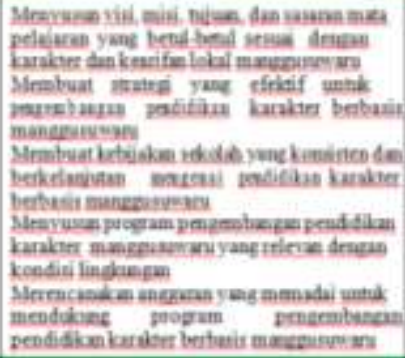 & 2 & 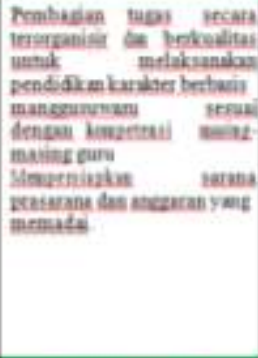 \\
\hline Xo & ACTEATINO & $\pi$ & CONTELLVE \\
\hline 3. & 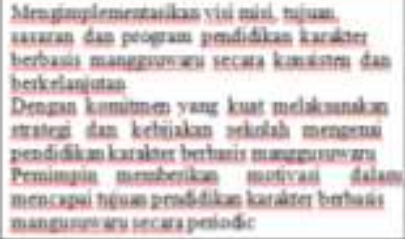 & $i$ & 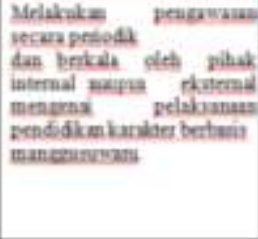 \\
\hline
\end{tabular}

\section{KESIMPULAN}

Berdasarkan hasil dan pembahasan di atas, mengenai gaya kepemimpinan kepala sekolah berbasis kearifan lokal manggusu waru pada Madrasah Aliyah Negeri 2 Kota Bima, maka dapat di simpulkan sebagai berikut:

1. Pelaksanaan kepemimpinan kepala berbasis manggusu waru di MAN 2 Kota Bima dibuktikan melalui program Pokok Menejemen Pendidikan untuk Penguatan Kompetensi Guru tentang Pendidikan Karakter Berbasis Manggusu Waru, yang telah dirumuskan kedalam restat sekolah dengan penuh perencanaan (planning), pengorganisasiaan (organizing), 
memberikan pengarahan (actuating), dan pengawasan (controlling).

2. Pelaksanaan kepemimpinan kepala berbasis manggusu waru di MAN 2 Kota Bima pada aspek perencanaanya menentukan strategi, kebijakan, taktik menjadi satu paket program harian selama 7 hari kegiatan pembelajaran di sekolah dengan mengintegrasikanya dengan delapan karakteristik manggusu waru ke dalam program tersebut.

\section{DAFTAR PUSTAKA}

Ali, Hasan. (2014). Maja Labo Dahu \& Nggusu Waru: Prinsip Hidup \& Pola Kepemimpinan Masyarakat Bima. Makassar: Lembaga Penerbitan Universitas Hasanudin(LEPHAS)

Muhaimin, Suti'ah dan Prabowo. (2010). Manajemen Pendidikan Aplikasi dalam Penyusunan Rencana Pengembangan Sekolah. Jakarta:Kencana.

Rosenbusch, Katie. (2013). Effective Leadership. European Journal Of Training and Development, Vol. 37, pp. 781-783.

Septiana, dkk. (2013). Pengaruh kepemimpinan kepala sekolah dan motivasi kerja terhadap kinerja guru smp negeri. JUPE UNS, 2(1) 107-118.

Tilaar. H.A.R. (2015). Pedagogis Teoritis Untuk Indonesia. Jakarta. Buku Kompas. 